\title{
Characteristics of atopic asthma and non-atopic asthma in the Study of Asthma, Genes and the Environment (SAGE) Cohort at 11-13 years
}

\author{
$\mathrm{J} \mathrm{Pitt}^{1 *}, \mathrm{AB}$ Becker ${ }^{2}, \mathrm{~A} \mathrm{Kozyrskyj}^{3}$ \\ From AllerGen NCE Inc.'s Fifth Annual Research Conference: Innovation from Cell to Society \\ Québec City, QC, Canada. 7-9 February 2010
}

\section{Objective/purpose}

Atopic and non-atopic asthma represent distinct phenotypes of childhood asthma. We hypothesize that there is an association between overweight/obesity and asthma in the absence of atopy and sought to further characterize these phenotypes at 11-13 years of age in a Canadian cohort.

\section{Methods}

The SAGE cohort includes 109 children with allergistdiagnosed atopic asthma (AA), 38 non-atopic asthmatics (NAA) and 185 control patients at the age of 11-13 years. Information on asthma symptoms and home environment was obtained from questionnaires. Anthropometric measurements and blood pressures were obtained. Spirometry was performed and cholesterol, LDL, HDL were measured. Statistical analysis was performed with SPSS- 17.

\section{Findings}

NAA (7.8\%) was less common than AA (22.4\%).NAA vs. AA was $9.9 \% / 20.8 \%$ in females, $6.2 \% / 23.6 \%$ in males. Mean FEV1\% predicted ( $87.8 \%$ vs. $87.3 \%$ ) did not differ between the NAA's and AA's. Wheezing episodes in the last year ( 2.3 vs. $2.7 \mathrm{p}=0.426)$ and episodes of sleep disturbances due to wheeze ( 0.7 vs. $0.5 \mathrm{p}=0.280$ ) were not significantly different. NAA's had slightly, but not significantly higher total cholesterol $(4.0 \mathrm{mmol} / \mathrm{L}$ vs. $3.9 \mathrm{mmol} / \mathrm{L})$, LDL $(2.2$ $\mathrm{mmol} / \mathrm{L}$ vs. $2.0 \mathrm{mmol} / \mathrm{L})$ and lower HDL $(1.4 \mathrm{mmol} / \mathrm{L}$ vs. $1.49 \mathrm{mmol} / \mathrm{L})$. For children with BMI $>85 \%$ ile $(\mathrm{n}=144)$, NAA's had higher mean cholesterol $(\mathrm{p}=0.08)$. NAA's also had marginally higher systolic blood pressure $(115.5 \mathrm{mmHg}$ vs. $113 \mathrm{mmHg}$ ) but not statistically significant. Mean waist circumference $(75.7 \mathrm{~cm}$ vs. $71.2 \mathrm{~cm})$ and weight $(54.6 \mathrm{~kg}$ vs.

'Winnipeg Children's Hospital - Winnipeg/CA, Canada

Full list of author information is available at the end of the article
$50.7 \mathrm{~kg}$ ) were higher in the NAA group but also not statistically significant. Early life tobacco exposure had an important influence on our subtypes. Interestingly, mothers of non-atopic asthmatics smoked fewer cigarettes/day in the first year of life (1.11 vs. $1.71 \mathrm{p}=0.025)$.

\section{Deliverables}

There is a trend towards higher cholesterol levels in overweight NAA's. There are no significant differences for asthma control between NAA's and AA's or blood lipids. AA's do have a higher burden of maternal tobacco smoke exposure in the first year of life than their NAA counterparts. This may suggest that environmental tobacco exposure is a risk factor in sensitization of AA's. We speculate that Vitamin D levels (a metabolite of cholesterol) may differ between the groups and analysis related to this is ongoing.

\section{Relevance}

It is increasingly important to better define phenotypes of asthma, especially in children. These findings will help to direct a focus for future and ongoing AllerGen research including the CHILD Study.

\section{Author details}

${ }^{1}$ Winnipeg Children's Hospital - Winnipeg/CA, Canada. ${ }^{2}$ Health Sciences Centre, Children's Hospital of Winnipeg - Winnipeg/CA, Canada. ${ }^{3}$ University of Alberta - Edmonton/CA, Canada.

Published: 26 November 2010

\section{doi:10.1186/1710-1492-6-S3-P6}

Cite this article as: Pitt et al:: Characteristics of atopic asthma and nonatopic asthma in the Study of Asthma, Genes and the Environment (SAGE) Cohort at 11-13 years. Allergy, Asthma \& Clinical Immunology 2010 6(Suppl 3):P6. 